\title{
The Changing Landscape of Uncomplicated Gram-Negative Bacteremia: A Narrative Review to Guide Inpatient Management
}

\author{
Jeannie D Chan, PharmD, MPH',2,34*, Chloe Bryson-Cahn, MD 3,4, Zahra Kassamali-Escobar, PharmD 2,5, \\ John B Lynch, MD, MPH ${ }^{3,4}$, Anneliese M Schleyer, MD, MHA 4,6
}

\begin{abstract}
${ }^{1}$ Department of Pharmacy, Harborview Medical Center, UW Medicine, Seattle, Washington; ${ }^{2}$ School of Pharmacy, University of Washington, Seattle, Washington; ${ }^{3}$ Department of Medicine, Division of Allergy \& Infectious Diseases, Harborview Medical Center, UW Medicine, Seattle, Washington; ${ }^{4}$ School of Medicine, University of Washington, Seattle, Washington; ${ }^{5}$ Department of Pharmacy, Valley Medical Center, UW Medicine, Renton, Washington; ${ }^{6}$ Hospital Medicine, Department of Medicine, Division of General Internal Medicine, Harborview Medical Center, UW Medicine, Seattle, Washington.
\end{abstract}

Gram-negative bacteremia secondary to focal infection such as skin and soft-tissue infection, pneumonia, pyelonephritis, or urinary tract infection is commonly encountered in hospital care. Current practice guidelines lack sufficient detail to inform evidence-based practices. Specifically, antimicrobial duration, criteria to transition from intravenous to oral step-down therapy, choice of oral antimicrobials, and reassessment of follow-up blood cultures are not addressed. The presence of bacteremia is often used as a justification for a prolonged course of antimicrobial therapy regardless of infection source or clinical response. Antimicrobials are lifesaving but not benign. Prolonged antimicrobial exposure is associated with adverse effects, increased rates of Clostridioides difficile infection, antimicrobial resistance, and longer hospital length of stay.
Emerging evidence supports shorter overall duration of antimicrobial treatment and earlier transition to oral agents among patients with uncomplicated Enterobacteriaceae bacteremia who have achieved adequate source control and demonstrated clinical stability and improvement. After appropriate initial treatment with an intravenous antimicrobial, transition to highly bioavailable oral agents should be considered for total treatment duration of 7 days. Routine follow-up blood cultures are not cost-effective and may result in unnecessary healthcare resource utilization and inappropriate use of antimicrobials. Clinicians should incorporate these principles into the management of gramnegative bacteremia in the hospital. Journal of Hospital Medicine 2020;15:746-753. (c) 2020 Society of Hospital Medicine ncomplicated bacteremia, while not precisely defined in the literature, generally implies bacteremia in the absence of a persistent or difficult-to-eradicate infectious source. Bacteremia secondary to focal infections such as skin and soft-tissue infection, pneumonia, pyelonephritis, or urinary tract infection (UTI) accounts for up to $25 \%$ of bloodstream infections (BSIs) and usually resolves with prompt and appropriate antimicrobial therapy. ${ }^{1,2}$ Current practice guidelines do not adequately address key aspects of the optimal management of gram-negative (GN)-BSI commonly encountered in hospital care..$^{3-7}$ Notably, antimicrobial duration, criteria to transition from intravenous (IV) to oral step-down therapy, choice of oral antimicrobials, and reassessment of follow-up blood cultures have not been addressed. In the absence of consensus guidelines, clinicians rely on "conventional wisdom" and clinical experience, which may not be supported by scientific rigor. A

*Corresponding Author: Jeannie D Chan, PharmD, MPH; Email: jdchan@ uw.edu; Telephone: 206-744-5944.

Published online first August 19, 2020.

Received: December 2, 2019; Revised: February 13, 2020;

Accepted: March 19, 2020

() 2020 Society of Hospital Medicine DOI 10.12788/jhm.3414 growing body of research now challenges some long-standing practices once thought to be standard of care.

In this narrative review, we aim to examine and synthesize emerging information to provide an evidence-based framework in the management of hospitalized patients with GN-BSI. We highlight the unintended consequences and potential harms of excessive antimicrobial exposure and focus on areas in the fundamental approach to duration of therapy, the role of oral antimicrobials, and usefulness of follow-up blood cultures. A comprehensive search of the published literature was performed in PubMed with an emphasis on articles published during 2015-2019 with use of search terms including gram-negative bacteremia, duration, antibiotics, adverse effects, intravascular catheter, and follow-up blood cultures.

\section{ANTIMICROBIAL RISKS: 'PRIMUM NON NOCERE'}

Antimicrobial overuse is common and may be driven by concerns for undertreatment. Clinicians may believe that prolonged antimicrobial therapy maximizes cure rates, with treatment duration often defined arbitrarily by a fixed number of "Constantine-units" (dating back to the ancient Roman emperor's decree of 7 days in a week). ${ }^{8-10}$ Recent publications refute this notion and point out that the harms of overprescribing outweigh the perceived benefits of longer treatment duration. 
Antimicrobials are lifesaving but not benign; adverse effects are common and costly to our patients and healthcare system. Among 1,488 hospitalized adults who received at least 24 hours of systemic antimicrobials, $20 \%$ had an antimicrobial-associated adverse event, mostly gastrointestinal, renal, or hematologic in nature. ${ }^{11}$ Prolonged duration of antimicrobials is further associated with adverse effects such as antimicrobial-associated diarrhea, increased rates of Clostridioides difficile infection (CDI), emergence of antimicrobial resistance, and longer hospital length of stay (LOS). ${ }^{11-15}$ Vaughn and colleagues conducted the largest observational study to date, evaluating antimicrobial prescriptions for the treatment of nearly 6,500 adults with community-acquired pneumonia in a 43-hospital consortium in Michigan. ${ }^{14}$ More than two-thirds of patients received antimicrobial courses (median 8 days) that exceeded guidelinerecommended duration. Patients who received longer antimicrobial courses did not have reduced mortality, readmission, or emergency department visits. More importantly, each excess day of treatment was associated with a relative $5 \%$ increase in the odds of antimicrobial-associated adverse effects reported by patients. This is further supported by national and state hospital data that antimicrobial-associated adverse events are an independent predictor of longer LOS. ${ }^{12}$

$\mathrm{CDI}$ is commonly linked to destructive changes to the indigenous microbiota of the intestinal flora caused by antimicrobial administration. Stevens and colleagues identified 7,792 hospitalized patients who received at least 2 consecutive days of antimicrobial therapy ${ }^{13}$; comparing 241 cases of CDI with the control group, they observed a dose-dependent risk of CDI associated with increasing cumulative dose, number of antimicrobials, and days of antimicrobial exposure. Compared with patients who received fewer than 4 days of antimicrobials, the adjusted hazard ratios (aHR) for those who received 4-7 days or 8-18 days of therapy were $1.4(95 \% \mathrm{Cl}, 0.8-2.4)$ and $3.0(95 \% \mathrm{Cl}, 1.9-5.0)$, respectively. This correlates to a threefold increase in CDI risk for patients who received more than 7 days of antimicrobials. More specifically, the empiric use of antipseudomonal B-lactams (APBL) for more than 48 hours was also found to be an independent risk factor for $\mathrm{CDI}$ among 808 patients with Enterobacteriaceae BSI. ${ }^{16}$ The risk of $\mathrm{CDI}$ within 90 days of $\mathrm{BSI}$ was higher among those who received $>48$ hours of APBL than it was among those who received $\leq 48$ hours $(H R, 3.6$; $95 \% \mathrm{Cl}, 1.5-9.9)$.

While $C$ difficile may be the most well-known pathogen implicated in antimicrobial usage, the incidence of multidrugresistant (MDR) organisms, either as infectious or colonizing pathogens, is also tied to antimicrobial exposure. Among patients receiving systemic antimicrobials, 6\% developed an MDR infection within 90 days. ${ }^{11}$ Over a 5-year period, Teshome and colleagues evaluated 7,118 critically ill patients and demonstrated that prolonged exposures to APBLs increased the risk of new antimicrobial resistance within 60 days. ${ }^{15}$ This resistance pattern was not an institutional or environmental finding but a patient-level finding. For each additional day of cefepime or piperacillin/tazobactam received, the risk of new antimicrobial resistance was increased by $8 \%$. The authors concluded that defining a piperacillin/tazobactam course as 10 vs 7 days would re- sult in a $24 \%$ higher relative risk of resistance per patient related to those 3 additional days of antimicrobial exposure.

Catheter complications including thrombophlebitis, infiltration, and infection are serious and frequent problems associated with IV medication administration. ${ }^{17}$ Even with short-term use, peripherally inserted central catheters (PICCs) carry a substantial risk of venous thrombosis (superficial and deep veins). The incidence of deep vein thrombosis (DVT) for PICCs is estimated between $5 \%$ and $15 \%$ for hospitalized patients and $2 \%$ and $5 \%$ for ambulatory patients. ${ }^{18} \mathrm{~A}$ recent randomized controlled trial (RCT) of oral vs IV antimicrobials for bone and joint infections reported that, compared with patients randomized to oral antimicrobials, those randomized to IV antimicrobials were more likely to have catheter complications $(9.4 \%$ vs $1.0 \%$; $P<.001)$ and to discontinue therapy earlier (18.9\% vs $12.8 \%$; $P=.006) .{ }^{19}$ Median hospital stay was also significantly longer in the IV group (14 days vs 11 days; $P<.001$ )

\section{SHORTEST EFFECTIVE DURATION: LESS MAY BE MORE}

Optimization of antimicrobial duration has long been recognized as one of the key strategies in reducing unnecessary antimicrobial exposure, yet high-quality evidence on comparative effectiveness of duration in the setting of bacteremia has been limited until recently. ${ }^{20}$ The presence of bacteremia is often used as a justification for prolonged courses of antimicrobial regardless of infection source or clinical response. The Infectious Diseases Society of America guidelines suggest 7 to 14 days of treatment for intravascular catheter-associated gram-negative bacteremia, but the optimal duration for noncatheter-related gram-negative bacteremia is not addressed. ${ }^{21}$ This lack of clear guidance and the historical scarcity of robust data make it difficult to inform best practices, which leads to wide variability in clinical practice and 14 days being the most prescribed duration. ${ }^{22,23}$

Pooled clinical trials' data from subsets of patients with bacteremia and those from observational studies have been the best available evidence for the treatment duration of GN-BSI until recently (Table 1). ${ }^{24-32}$ Two meta-analyses evaluating RCTs of adult and pediatric patients with pyelonephritis, UTI, peritonitis, and pneumonia found no differences in clinical failure, microbiologic cure, or survival between short and long courses of therapy in the subset of patient with associated bacteremia. ${ }^{24,25}$ Six heterogeneous RCTs of short vs long courses of therapy for complicated UTI or pyelonephritis reported no differences in clinical cure rates in the subset of patients with associated GN-BSI. ${ }^{2}$ The observational studies outlined in Table 1 are also consistent with RCT results supporting noninferiority in clinical cure and mortality outcomes between short and long courses of therapy. ${ }^{26-32}$ These findings may also be extrapolated to immunocompromised hosts given a considerable representation of $10 \%$ to $47 \%$ of the study population with immunosuppressive conditions.

Nelson and colleagues conducted the only retrospective study to date reporting conflicting results of higher risk of treatment failure (defined as composite endpoint of mortality 
TABLE 1. Evidence Summary of Studies Evaluating Duration of Therapy

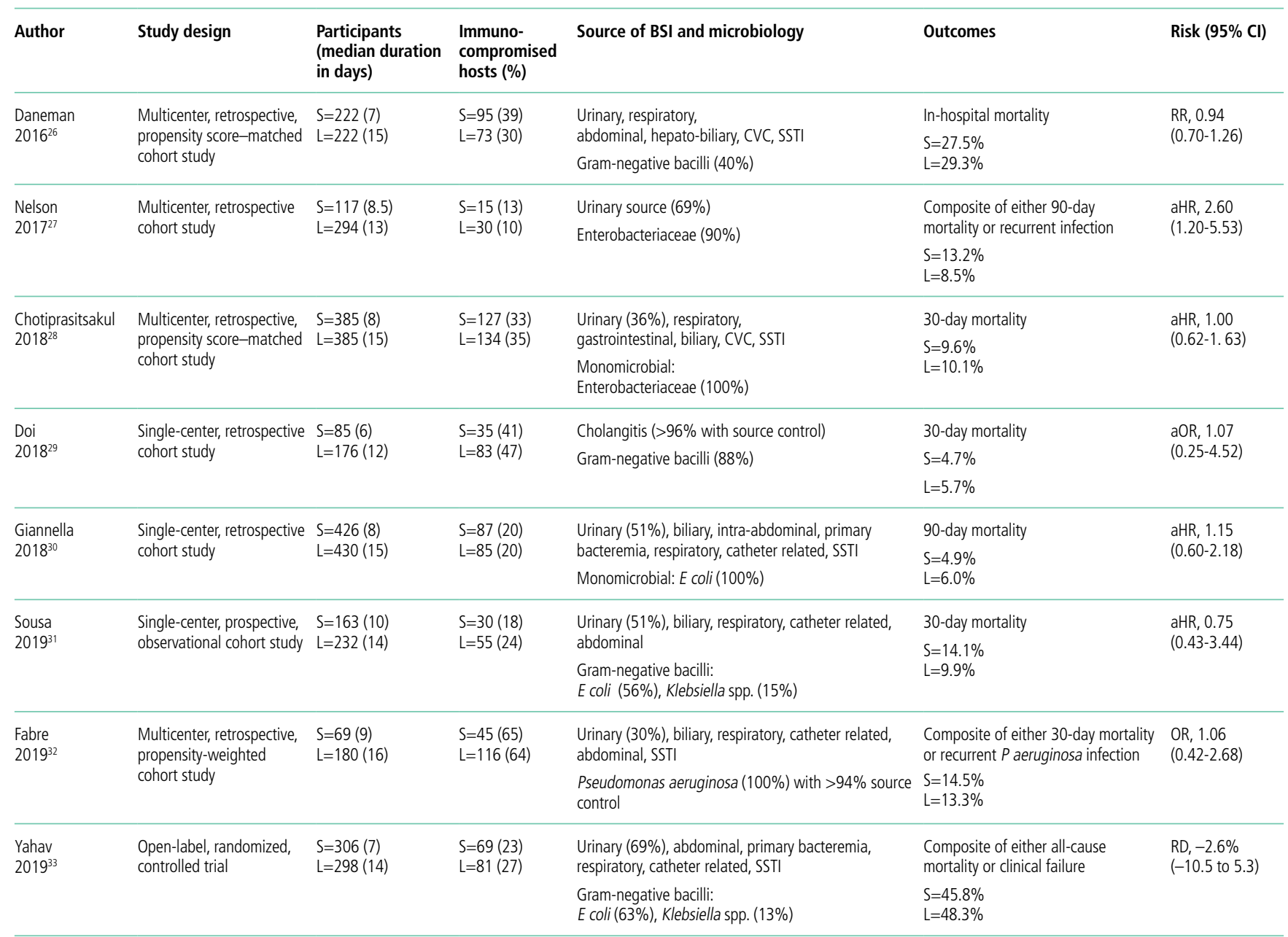

Abbreviations: aHR, adjusted hazard ratio; aOR, adjusted odds ratio; $\mathrm{BSI}$, bloodstream infection; Cl, confidence interval; CVC, central venous catheters; E coli, Escherichia coli; $\mathrm{HR}$, hazard ratio; $\mathrm{L}$, long duration; OR, odds ratio; RD, risk difference; RR, relative risk; S, short duration; SSTI, skin and soft-tissue infection.

or recurrent infection within 90 days of index BSI) in patients receiving a short course of therapy. ${ }^{27}$ However, the difference was driven by 90 -day mortality ( $8.2 \%$ vs $3.3 \% ; P=.04)$ not recurrent infection (6.7\% vs $6.5 \% ; P=0.93$ ). Giannella and colleagues also evaluated 90-day mortality as a primary endpoint in a much larger cohort of over 850 patients in Italy and found no difference in mortality rates between short and long courses of antimicrobials. ${ }^{30}$

Yahav and colleagues conducted the first well-designed open-label RCT comparing short and long courses of antimicrobials in uncomplicated GN-BSI. ${ }^{33}$ This noninferiority study randomized more than 600 hospitalized patients with adequate source control who were afebrile and hemodynamically stable for $\geq 48$ hours to receive either 7 days or 14 days of therapy. The source of infections was predominantly urinary (68\%), and the causative pathogens were $90 \%$ Enterobacteriacae, including $20 \%$ MDR strains. The primary outcome was a composite of 90-day all-cause mortality or clinical failure defined as either relapse of bacteremia, local or distant complications, readmission, or extended hospital stay $>14$ days. The authors reported no statistically significant differences in the primary outcome between short (45.8\%) and long (48.3\%) courses of treatment. In the prespecified post hoc analysis designed to evaluate infection-related outcomes at an earlier time frame, there were no observed differences in complications, relapses, or mortality between study groups at 14 and 28 days. Further subgroup analysis demonstrated similar results among patients with MDR pathogens, primarily extended-spectrum B-lactamases (ESBL). Interestingly, there was a more rapid return to baseline activity and functional capacity among patients randomized to a short course of therapy. The authors acknowledged that the patients' perception of illness while taking antimicrobials may have influenced self-reported well-being and functional performance. In exploratory analysis, prolonged hospitalization and readmission were excluded from the primary study endpoint to mirror outcomes assessed by Nelson and colleagues. There were no statistically significant differences in death, relapses, or complications between groups randomized to short $(18.6 \%)$ or long $(15.1 \%)$ courses of therapy, with a risk difference of $3.5 \%(95 \% \mathrm{Cl},-2.5 \%$ to $9.5 \%)$ in this study population. 
TABLE 2. Evidence Summary of Studies Evaluating Continued Intravenous Therapy vs Conversion of Intravenous to Oral Antimicrobials

\begin{tabular}{|c|c|c|c|c|c|c|c|}
\hline Author & Study design & $\begin{array}{l}\text { Participants and } \\
\text { antimicrobial }\end{array}$ & $\begin{array}{l}\text { Median days } \\
\text { to PO }\end{array}$ & Source of BSI and microbiology & Outcome & $\begin{array}{l}\text { Risk } \\
(95 \% \mathrm{Cl})\end{array}$ & $\begin{array}{l}\text { Length of stay } \\
\text { (days) }\end{array}$ \\
\hline $\begin{array}{l}\text { Amodio-Groton } \\
1996^{39}\end{array}$ & Single-center RCT & $\begin{array}{l}\text { IV }=26 \\
P O=24 \\
\text { Ciprofloxacin }\end{array}$ & 3 & $\begin{array}{l}\text { Urinary }(66 \%) \\
\text { Gram-negative bacilli: } \\
\text { E coli }(64 \%) \\
\text { K pneumoniae }(14 \%)\end{array}$ & $\begin{array}{l}\text { Clinical resolution and } \\
\text { improvement } \\
\text { IV }=92.3 \% \\
\text { PO }=95.8 \%\end{array}$ & $\begin{array}{l}\mathrm{RD}, 3.5 \% \\
(P=\mathrm{NS})\end{array}$ & $\begin{array}{l}\text { IV }=15.7 \\
P O=9.8 \\
P<.05\end{array}$ \\
\hline $\begin{array}{l}\text { Park } \\
2014^{40}\end{array}$ & Multicenter RCT & $\begin{array}{l}\text { IV }=30 \\
P O=29 \\
\text { Ciprofloxacin }\end{array}$ & 6 & $\begin{array}{l}\text { Cholangitis (100\%) } \\
\text { Gram-negative bacilli: } \\
\text { E coli }(76 \%) \\
\text { K pneumoniae }(14 \%)\end{array}$ & $\begin{array}{l}\text { 30-day microbiologic } \\
\text { eradication } \\
\text { IV }=93.3 \% \\
\text { PO }=93.1 \%\end{array}$ & $\begin{array}{l}\mathrm{RD}_{1}-0.2 \% \\
(-0.13 \text { to } 0.14)\end{array}$ & $\begin{array}{l}\text { IV }=12.3 \\
P O=10.8 \\
P=.02\end{array}$ \\
\hline $\begin{array}{l}\text { Reiger } \\
2017^{41}\end{array}$ & $\begin{array}{l}\text { Single-center, } \\
\text { retrospective } \\
\text { cohort study }\end{array}$ & $\begin{array}{l}\text { IV }=106 \\
P O=135 \\
\text { FQ: } 65 \% \\
\text { BL: } 19 \% \\
\text { T/S: } 9 \%\end{array}$ & 4 & $\begin{array}{l}\text { Urinary }(100 \%) \\
\text { Enterobacteriaceae: } \\
\text { E coli }(57 \%) \\
\text { K pneumoniae }(23 \%)\end{array}$ & $\begin{array}{l}\text { Treatment failure } \\
\text { IV }=3.8 \% \\
\mathrm{PO}=8.2 \% \\
P=0.19\end{array}$ & NA & $\begin{array}{l}\mathrm{IV}=7.1 \\
\mathrm{PO}=4.6 \\
P<.001\end{array}$ \\
\hline $\begin{array}{l}\text { Thurber } \\
2019^{42}\end{array}$ & $\begin{array}{l}\text { Single-center, } \\
\text { retrospective } \\
\text { cohort study }\end{array}$ & $\begin{array}{l}\text { IV }=82 \\
P O=264 \\
\text { FQ: } 87 \% \\
\text { BL: } 5 \% \\
\text { T/S: } 8 \%\end{array}$ & 3 & $\begin{array}{l}\text { Urinary }(100 \%) \\
\text { Gram-negative bacilli: } \\
\text { E coli }(66 \%) \\
\text { Klebsiella spp (14\%) }\end{array}$ & $\begin{array}{l}\text { Treatment failure } \\
\text { IV }=2.4 \% \\
\text { PO }=1.5 \%\end{array}$ & $\begin{array}{l}H R, 0.62 \\
(0.11-3.39)\end{array}$ & $\begin{array}{l}\mathrm{IV}=6 \\
\mathrm{PO}=4 \\
P<.001\end{array}$ \\
\hline $\begin{array}{l}\text { Tamma } \\
2019^{43}\end{array}$ & $\begin{array}{l}\text { Multicenter, } \\
\text { propensity } \\
\text { score-matched, } \\
\text { retrospective } \\
\text { cohort study }\end{array}$ & $\begin{array}{l}\text { IV }=739 \\
\text { PO = } 739 \\
\text { FQ (High bio): } 70 \% \\
\text { BL (Low bio): } 17 \% \\
\text { T/S (High bio): } 13 \%\end{array}$ & 3 & $\begin{array}{l}\text { Urinary ( } 40 \%), \mathrm{Gl} \text {, catheter, biliary, } \\
\text { respiratory, SSTI } \\
\text { Enterobacteriaceae: } \\
\text { E coli }(44 \%) \\
\text { K pneumoniae }(34 \%)\end{array}$ & $\begin{array}{l}\text { 30-day mortality } \\
\text { IV }=13.4 \% \\
\text { PO }=13.1 \% \\
\text { 30-day recurrent } \\
\text { bacteremia } \\
\text { IV }=0.5 \% \\
P O=0.8 \%\end{array}$ & $\begin{array}{l}\text { 30-day mortality } \\
\mathrm{HR}=1.03 \\
(0.82-1.30) \\
\text { 30-day recurrent } \\
\text { bacteremia } \\
\mathrm{HR}, 0.82 \\
(0.33-2.01)\end{array}$ & $\begin{array}{l}\mathrm{IV}=7 \\
\mathrm{PO}=5 \\
P<.001\end{array}$ \\
\hline
\end{tabular}

Abbreviations: bio, bioavailability; BL, B-lactam; BSI, bloodstream infection; Cl, confidence interval; E coli, Escherichia coli; $\mathrm{FQ}$, fluoroquinolones; GI, gastrointestinal; HR, hazard ratio; IV, intravenous; K pneumoniae, Klebsiella pneumoniae; NS, not significant; PO, oral; RCT, randomized controlled trial; RD, risk difference; SSTI, skin and soft-tissue infection; $\mathrm{T} / \mathrm{S}$, trimethoprim/sulfamethoxazole.

Patients with Pseudomonas aeruginosa BSI often have more chronic medical comorbidities, immunocompromised conditions, higher severity of illness, and more indwelling catheters than do patients with Enterobacteriaceae BSI. ${ }^{32} \mathrm{It}$ is uncertain whether shorter duration of therapy is generalizable to this population, given that Pseudomonas accounted for a relatively low number (8\%) of infections in the published RCT. ${ }^{33}$ Fabre and colleagues included high-risk patients with $>65 \%$ of the cohort with severe immunocompromised conditions consisting of stem cell transplantation, recent chemotherapy, or neutropenia, and they reported no difference in 30-day mortality or recurrent infections among patients with pseudomonal BSI regardless of duration of therapy. ${ }^{32}$

\section{ORAL TREATMENT: CHALLENGING TRADITIONAL DOGMA}

It is a well-accepted standard of practice that BSI are treated with upfront IV antimicrobials that can rapidly achieve therapeutic serum concentration. Whether IV administration is warranted for the entire duration of therapy, though, remains controversial. Even in an era of highly bioavailable oral antimicrobials, clinicians often assume that IV antimicrobials are more potent and efficacious than oral antimicrobials. ${ }^{8,9}$ This belief has contributed to the dogma that IV therapy is necessary irrespective of the associated risks and costs. Oral antimicrobials are often over- looked as alternatives despite established benefits in avoiding complications associated with IV catheters, decreasing hospital LOS, and improving quality of life. ${ }^{34}$ There are promising clinical data in support of the efficacy and safety of transitioning from sequential-IV to highly bioavailable oral agents for the treatment of uncomplicated bacteremia caused by both gram-positive and gram-negative pathogens. ${ }^{2,35}$ Highly bioavailable oral antimicrobials are also increasingly integrated as sequential therapy for deep-seated infections in bone and joint infections, such as vertebral osteomyelitis. ${ }^{19,36}$ These findings have been confirmed in a recent RCT demonstrating noninferiority of oral antimicrobial combinations after satisfactory clinical responses to at least 10 days of IV therapy, compared with continued IV regimens, in left-sided infective endocarditis. ${ }^{36}$ While not a prespecified endpoint, hospital LOS was shorter among patients randomized to oral antimicrobials.

Although there are no large-scale RCTs sufficiently powered to address the role of oral antimicrobials in the treatment of uncomplicated GN-BSI, some insights can be gleaned from the existing literature (Table 2). In the RCT establishing noninferiority of short vs long courses of antimicrobials for uncomplicated GN-BSI, the majority of patients randomized to 7 days vs 14 days of therapy, $64 \%$ and $81 \%$, respectively, were de-escalated to oral antimicrobials, with fluoroquinolones (FQs) being the predominant (>70\%) oral regimen, followed by trimethoprim/ 
TABLE 3. Evidence Summary of Studies Comparing Various Oral Regimens for Definitive Therapy

\begin{tabular}{|c|c|c|c|c|c|c|}
\hline Author & Study design & Participants & $\begin{array}{l}\text { Median days } \\
\text { to PO }\end{array}$ & Source of BSI and microbiology & Outcome & $\begin{array}{l}\text { Risk } \\
(95 \% \mathrm{Cl})\end{array}$ \\
\hline $\begin{array}{l}\text { Kutob } \\
2016^{45}\end{array}$ & $\begin{array}{l}\text { Multicenter, } \\
\text { retrospective } \\
\text { cohort study }\end{array}$ & $\begin{array}{l}\text { High bio }=106 \\
\text { Mid bio }=179 \\
\text { Low bio }=77\end{array}$ & Mean, 4.7 & $\begin{array}{l}\text { Urinary source }(67 \%) \\
\text { Gram-negative bacilli: } \\
\text { E coli }(67 \%) \\
\text { K pneumoniae }(14 \%)\end{array}$ & $\begin{array}{l}\text { Composite of either } \\
90 \text {-day mortality or recurrence } \\
\text { High bio }=2 \% \\
\text { Mid bio }=12 \% \\
\text { Low bio }=14 \% \\
P=.02\end{array}$ & $\begin{array}{l}\text { High-bio = REF } \\
\text { Mid-bio aHR, } 5.9(1.6-38.5) \\
\text { Low-bio aHR, } \\
7.7(1.9-51.5)\end{array}$ \\
\hline $\begin{array}{l}\text { Mercuro } \\
2018^{44}\end{array}$ & $\begin{array}{l}\text { Single-center, } \\
\text { retrospective } \\
\text { cohort study }\end{array}$ & $\begin{array}{l}\mathrm{BL}=84 \\
\mathrm{FQ}=140\end{array}$ & 3 & $\begin{array}{l}\text { Urinary }(71 \%) \text {, intra-abdominal, } \\
\text { SSTI, respiratory, catheter } \\
\text { Enterobacteriaceae: } \\
\text { E coli }(71 \%) \\
\text { K pneumoniae }(17 \%)\end{array}$ & $\begin{array}{l}\text { Clinical success } \\
\mathrm{BL}=86.9 \% \\
\mathrm{FQ}=87.1 \%\end{array}$ & $\mathrm{RD}, 0.2 \%(97.5 \% \mathrm{Cl},-10.3$ to 10.7$)$ \\
\hline $\begin{array}{l}\text { Tamma } \\
2019^{43}\end{array}$ & $\begin{array}{l}\text { Multicenter, } \\
\text { propensity } \\
\text { score-matched, } \\
\text { retrospective } \\
\text { cohort study }\end{array}$ & $\begin{array}{l}\text { High bio }=617 \\
\text { Low bio }=122\end{array}$ & 3 & $\begin{array}{l}\text { Urinary (40\%), GI, catheter, } \\
\text { biliary, respiratory, SSTI } \\
\text { Enterobacteriaceae: } \\
\text { E coli (46\%) } \\
\text { K pneumoniae (32\%) }\end{array}$ & $\begin{array}{l}\text { 30-day mortality } \\
\text { High bio }=11.0 \% \\
\text { Low bio }=12.3 \%\end{array}$ & $\begin{array}{l}H R, 1.05 \\
(0.67-1.66)\end{array}$ \\
\hline \multirow[t]{2}{*}{$\begin{array}{l}\text { Punjabi } \\
2019^{46}\end{array}$} & $\begin{array}{l}\text { Systematic review } \\
\text { and meta-analysis }\end{array}$ & $\begin{array}{l}\mathrm{FQ}=1,489 \\
\mathrm{BL}=623 \\
\mathrm{~T} / \mathrm{S}=177\end{array}$ & 3-5 & $\begin{array}{l}\text { Urinary }(40 \%-100 \%) \\
\text { Gram-negative bacilli (100\%) }\end{array}$ & $\begin{array}{l}\text { All-cause mortality } \\
\mathrm{FQ} \text { or } \mathrm{T} / \mathrm{S}=5.1 \% \\
\mathrm{BL}=3.5 \%\end{array}$ & $\begin{array}{l}\text { All-cause mortality } \\
\text { OR, } 1.13 \\
(0.69-1.87)\end{array}$ \\
\hline & & & & & $\begin{array}{l}\text { Recurrence } \\
\mathrm{FQ} \text { or } \mathrm{T} / \mathrm{S}=2.0 \% \\
\mathrm{BL}=5.5 \%\end{array}$ & $\begin{array}{l}\text { Recurrence } \\
\text { OR, 2.06 } \\
(1.18-3.61)\end{array}$ \\
\hline
\end{tabular}

Abbreviations: aHR, adjusted hazard ratio; bio, bioavailability; BL, B-lactam; Cl, confidence intervals; E coli, Escherichia coli; $\mathrm{FQ}$, fluoroquinolones; $\mathrm{Gl}$, gastrointestinal; $\mathrm{HR}$, hazard ratio; K pneumoniae, Klebsiella pneumoniae; OR, odds ratio; PO, oral; RD, risk difference; REF, reference; SSTI, skin and soft-tissue infection; T/S, trimethoprim/sulfamethoxazole.

sulfamethoxazole (T/S) and oral B-lactams. ${ }^{33}$

Despite the Food and Drug Administration warnings of the potentially permanent adverse effects involving tendons, muscles, joints, nerves, and most recently, aortic aneurysms and ruptures, ${ }^{37} \mathrm{FQ}$ remain a unique class of drugs with favorable pharmacodynamic and pharmacokinetic properties that achieve approximately equivalent serum and tissue concentration when administered either intravenously or orally. This advantage was recognized early on as a potential IV-sparing therapeutic option. A prospective RCT that evaluated oral vs IV ciprofloxacin as initial empiric therapy among 141 patients with pyelonephritis or complicated UTI (38\% with secondary BSI) reported no significant differences in microbiological failure or clinical response between the two treatment groups. ${ }^{38}$ Two small RCTs have also demonstrated the safety and effectiveness of sequential-IV antimicrobial to oral FQs in the setting of GN-BSI secondary to urinary source and cholangitis. ${ }^{39,40}$ Oral B-lactams, however, achieve substantially lower serum concentration than do their IV counterparts and, accordingly, may be less reliably effective. ${ }^{2}$

Five retrospective cohort studies have more directly investigated the role of oral antimicrobials in the setting of GN-BSI secondary to common focal infections (Table 2 and Table 3). ${ }^{41-45}$ Two observational studies reported no difference of treatment failure among patients who received IV-only therapy vs those who were switched to oral therapy in bacteremia secondary to UTIs. ${ }^{41,42}$ Catheter-associated complications were higher in the IV cohort (6.1\% vs $0.4 \% ; P=.03){ }^{42}$ In the largest multicenter cohort study to date, which included 1,478 patients with Enterobacteriaceae bacteremia, there was no difference in 30-day mortality or recurrent bacteremia between patients converted to oral step-down therapy and patients who received the full course of IV antimicrobials. ${ }^{43}$ Furthermore, the median hospital LOS was shorter ( 5 days vs 7 days; $P<.001$ ) among patients who were transitioned to oral therapy, a finding that is consistent with other studies. ${ }^{39-42}$ In their analysis, the oral antimicrobials were categorized as low-bioavailability (B-lactams) or high-bioavailability ( $F Q$ and $T / S$ ), and there was no difference in outcomes when results were stratified by bioavailability. Mercuro and colleagues reported similar clinical success among patients who received oral B-lactams and those who received FQs as stepdown therapy. ${ }^{44}$ Notably, patients were more likely to tolerate B-lactams without experiencing adverse effects than were those who received $\mathrm{FQs}(91.7 \%$ vs $82.1 \% ; P=.049)$. In contrast, Kutob and colleagues compared step-down oral antimicrobials categorized as low bioavailability (ß-lactams), moderate bioavailability (ciprofloxacin and T/S), and high bioavailability (levofloxacin). They reported that treatment failures were significantly higher among patients who received low-bioavailability (14\%) and moderate-bioavailability (12\%) antimicrobials, compared with those who received the high-bioavailability agent $(2 \% ; P=.02) .{ }^{45}$ Interestingly, the bioavailability of ciprofloxacin reaches $85 \%$ and T/S approaches $90 \%$, and they are often categorized as highly bioavailable agents in other studies. ${ }^{43,46}$ If they were reclassified as highly bioavailable agents, the study conclusions might differ. Nevertheless, the reported success with oral step-down therapy exceeded $85 \%$ in all five studies. ${ }^{41-45}$

It is important to acknowledge the possibility of unmeasured confounders in these retrospective, observational studies despite statistical adjustments and that they are likely underpowered to determine the clinical significance of oral bioavailability 
TABLE 4. Summary of Management Recommendations for Gram-Negative Bloodstream Infection

\begin{tabular}{lll}
\hline Management & Comments & Recommendations \\
\hline Follow-up blood cultures & Documentation of follow-up blood culture clearance is not associated with improved clinical care. & Avoid routine use of follow-up blood cultures. \\
\hline Oral antimicrobials & Oral antimicrobials are safe and effective. Consider oral antimicrobials with high bioavailability as step-down therapy. & $\begin{array}{l}\text { Transition to oral antimicrobials with clinical } \\
\text { improvement. }\end{array}$ \\
\hline Duration of antimicrobials & $\begin{array}{l}\text { Longer courses of antimicrobials are associated with adverse effects, including Clostridioides difficile infections, } \\
\text { emergence of antimicrobial resistance, catheter-related complications, and longer hospital length of stay. }\end{array}$ & $\begin{array}{l}\text { Prescribe a total } 7 \text { days of therapy } \\
\text { (intravenous and oral). }\end{array}$ \\
\hline
\end{tabular}

*Once patients demonstrate clinical improvement (are afebrile, have improved white blood cell count, are hemodynamically stable, achieve adequate source control)

of antimicrobials. In a meta-analysis of published studies and abstracts that included 2,289 patients with Enterobacteriaceae bacteremia, all-cause mortality was similar between patients de-escalated to an oral FQ, T/S, or B-lactam. ${ }^{46}$ Overall recurrence of infection (bacteremia or primary site) occurred more frequently in patients transitioned to oral B-lactams than FQs, but relapse of bacteremia was not statistically different between comparator groups. Bioavailability of the oral agents may not be the sole determinant of higher recurrence; adherence may be poor because of the more frequent dosing required for oral B-lactams to achieve targeted pharmacokinetics. Additionally, suboptimal dosing of oral B-lactams noted in the studies may have also contributed to the increased recurrences.

After source control has been achieved and bacterial inoculum burden is sufficiently reduced with appropriate upfront IV therapy, the bioavailability of oral antimicrobials may become less important. However, existing observational data indicate clinical experience is most established with highly bioavailable oral agents, particularly FQs, though the risks vs benefits require careful consideration. For now, the preferred oral agent remains uncertain and selections should be individualized based on susceptibility, patient factors, and other clinical considerations. More importantly, if there are no contraindications or concerns of malabsorption, oral step-down therapy should be initiated as soon as source control and good clinical responses have been achieved.

\section{TEST OF CURE: RECONSIDERING FOLLOW-UP BLOOD CULTURES}

Routine follow-up blood cultures (FUBCs) are strongly recommended in Staphylococcus aureus bacteremia because of the propensity for endovascular and metastatic infection, which dictates clinical decision-making regarding duration of therapy. In contrast, GN-BSI secondary to focal infections is usually transient, and the need for confirmation of blood culture clearance is less clear. The low yield of FUBC in many clinical settings suggests that it may not be helpful. ${ }^{47-50}$ Despite the questionable impact on the clinical management of GN-BSI, FUBCs are routinely ordered in the hospital. ${ }^{1,47}$ Although there is no high-quality evidence addressing the utility of FUBC, several observational studies suggest clinicians should reconsider routinely ordering FUBC.

Canzoneri and colleagues retrospectively evaluated 383 episodes of bacteremia with at least one FUBC drawn after the ini- tial blood culture. ${ }^{48}$ On average, 2.32 FUBC were performed per patient for GN-BSI episode, and only 8 patients (5.7\%) had persistent bacteremia. Specifically, only $3 \%$ had documented positive FUBC among patients with urinary tract source of infection. It was estimated that 17 FUBCs are needed to yield one positive result for GN-BSI. This finding is consistent with results from another study that examined 1,801 episodes of bacteremia, 901 of which were gram-negative organisms, predominantly (67\%) Escherichia coli and Klebsiella spp. ${ }^{49}$ Among GN-BSI episodes, FUBCs were performed in 247 cases, with 27 (10.9\%) cases demonstrating persistent bacteremia. A nested case-control analysis between patients with cleared or persistent bacteremia found a lower yield in FUBC with gram-negative organisms and a genitourinary source of infection. Moreover, persistent bacteremia did not influence a change in antimicrobial regimen. Kang and colleagues investigated 1,068 episodes of Klebsiella pneumoniae bacteremia, with FUBCs performed in 862 (80.7\%) cases despite only a $7.2 \%$ incidence of persistent bacteremia..$^{50}$ The independent risk factors associated with persistent bacteremia were intra-abdominal infection, solid organ transplantation, high Charlson comorbidity index score, and unfavorable treatment responses, which suggests the need for FUBC may be individualized rather than routine.

In the setting of GN-BSI in which the probability of persistent bacteremia is relatively low, especially in genitourinary sources of infection, FUBCs are not warranted. It is uncomfortable for patients and exposes them to harms of false-positive results, leading to antimicrobial administration with possible adverse effects, which can be further compounded by unnecessary testing, potentially missed alternative diagnosis, and increasing hospital LOS. ${ }^{1,51}$ Given the low yield of FUBC in GN-BSI, and the lack of association of persistent bacteremia with change in antimicrobial therapy or clinical outcomes, we recommend avoiding FUBC as a test of cure. Documentation of gram-negative blood culture clearance should be reserved for situations in which there is concern for deeper or otherwise uncontrolled source of infection.

\section{CONCLUSION}

The optimal management of gram-negative bacteremia in hospitalized patients is evolving. There is a growing body of evidence supporting shorter duration for a total of 7 days with oral step-down therapy as safe and effective for patients with uncomplicated Enterobacteriaceae bacteremia who have 
achieved adequate source control and demonstrated clinical stability and improvement. Although comparative data regarding the optimal duration of therapy in the setting of MDR strains such as ESBL Enterobacteriaceae and pseudomonal BSI are limited, available data appear promising in favor of shorter treatment duration with oral step-down therapy. Routine follow-up blood culture is not cost-effective and may result in unnecessary healthcare resource utilization and inap-

\section{References}

1. Cobrun B, Morris AM, Tomlinson G, Detsky AS. Does this adult patient with suspected bacteremia require blood culture? JAMA. 2012;308(5):502-511. https://doi.org/10.1001/jama.2012.8262

2. Sutton JD, Sayood S, Spivak ES. Top questions in uncomplicated, non-Staphylococcus aureus bacteremia. Open Forum Infect Dis. 2018;5(5):ofy087. https://doi.org/10.1093/ofid/ofy087

3. Metlay JP, Waterer GW, Long AC, et al. Diagnosis and treatment of adults with community-acquired pneumonia. an official clinical practice guideline of the American Thoracic Society and Infectious Diseases Society of America. Am J Respir Crit Care Med. 2019;200(7):e45-e67. https://doi.org/10.1164/ rccm.201908-1581ST

4. Kalil AC, Metersky ML, Klompas M, et al. Management of adults with hospital-acquired and ventilator-associated pneumonia: 2016 clinical practice guidelines by the Infectious Diseases Society of America and the American Thoracic Society. Clin Infect Dis. 2016;63(4):e61-e111. https://doi.org/10.1093/ $\mathrm{cid} / \operatorname{ciw} 353$

5. Stevens DL, Bisno AL, Chambers HF, et al. Practice guidelines for the diagnosis and management of skin and soft tissue infections: 2014 update by the Infectious Diseases Society of America. Clin Infect Dis. 2014;59(2):e10-e52. https://doi.org/10.1093/cid/ciu296

6. Solomkin JS, Mazuski JE, Bradley JS, et al. Diagnosis and management of complicated intra-abdominal infections in adults and children: guidelines by the Surgical Infection Society and the Infectious Diseases Society of America. Clin Infect Dis. 2010;50(2):133-164. https://doi.org/10.1086/649554

7. Gupta K, Hooton TM, Naber KG, et al. International clinical practice guidelines for the treatment of acute uncomplicated cystitis and pyelonephritis in women: a 2010 update by the Infectious Diseases Society of American and the European Society for Microbiology and Infectious Diseases. Clin Infect Dis. 2011;52(5):e103-e120. https://doi.org/10.1093/cid/ciq257

8. Cyriac JM, James E. Switch over from intravenous to oral therapy: a concise overview. J Pharmacol Pharmacother. 2014;5(2):83-87. https://doi. org/10.4103/0976-500X.130042

9. Broom J, Broom A, Adams K, Plage S. What prevents the intravenous to oral antibiotic switch? A qualitative study of hospital doctors' accounts of what influences their clinical practice. J Antimicrob Chemother. 2016;71(8):22952299. https://doi.org/10.1093/jac/dkw129

10. Spellberg B. The maturing antibiotic mantra: "shorter is still better." J Hosp Med. 2018;13(5):361-362. https://doi.org/10.12788/jhm.2904

11. Tamma PD, Avdic E, Li DX, Dzintars K, Cosgrove SE. Association of adverse events with antibiotic use in hospitalized patients. JAMA Intern Med. 2017;177(9):1308-1315. https://doi.org/10.1001/jamainternmed.2017.1938

12. Lin RY, Nuruzzaman F, Shah SN. Incidence and impact of adverse effects to antibiotics in hospitalized adults with pneumonia. J Hosp Med. 2009;4(2):E7E15. https://doi.org/10.1002/jhm.414

13. Stevens V, Dumyati G, Fine LS, Fisher SG, van Wijngaarden E. Cumulative antibiotic exposures over time and the risk of Clostridium difficile infection. Clin Infect Dis. 2011;53(1):42-48. https://doi.org/10.1093/cid/cir301.

14. Vaughn VM, Scott FA, Snyder A, et al. Excess antibiotic treatment duration and adverse events in patients with hospitalized pneumonia - a multihospital cohort study. Ann Intern Med. 2019;171(3):153-163. https://doi.org/10.7326/ M18-3640

15. Teshome BF, Vouri SM, Hampton N, Kollef MH, Micek ST. Duration of exposure to antipseudomonal B-lactam antibiotics in the critically ill and development of new resistance. Pharmacotherapy. 2019;39(3):261-270. https://doi. org/10.1002/phar.2201

16. Dychter SS, Gold DA, Carson D, Haller M. Intravenous therapy: a review of complications and economic considerations of peripheral access. J Infus Nurs. 2012;35(2):84-91. https://doi.org/10.1097/NAN.0b013e31824237ce

17. Seddon MM, Bookstaver PB, Justo JA, et al. Role of early de-escalation of antimicrobial therapy on risk of Clostridioides difficile infection following Enterobacteriaceae bloodstream infections. Clin Infect Dis. 2019;69(3):414-420. https://doi.org/10.1093/cid/ciy863 propriate use of antimicrobials. Table 4 provides a framework for the clinical management of GN-BSI in the hospital. Taken together, these steps will facilitate antimicrobial stewardship, limit unnecessary antimicrobial exposure, and improve quality of patient care.

Disclosures: The authors have no conflicts of interest to disclose.

18. Fallouh N, McGurik HM, Falnders SA, Chopra V. Peripherally inserted central catheter-associated deep vein thrombosis: a narrative review. Am J Med. 2015;128(7):722-738. https://doi.org/10.1016/j.amjmed.2015.01.027

19. Li HK, Rombach I, Zambellas $\mathrm{R}$, et al. Oral versus intravenous antibiotics for bone and joint infection. N Engl J Med. 2019;380:425-436. https://doi. org/10.1056/NEJMoa1710926

20. Hayashi Y, Peterson DL. Strategies for reduction in duration of antibiotic use in hospitalized patients. Clin Infect Dis. 2011;52(10):1232-1240. https://doi. org/10.1093/cid/cir063

21. Mermel LA, Allon M, Bouza E, et al. Clinical practice guidelines for the diagnosis and management of intravascular catheter-related infection: 2009 update by the Infectious Diseases Society of America. Clin Infect Dis. 2009;49(1):1-45. https://doi.org/10.1086/599376

22. Corona A, Bertolini G, Ricotta AM, Wilson A, Singer M. Variability of treatment duration for bacteraemia in the critically ill: a multinational survey. J Antimicrob Chemother. 2003;52(5):849-852. https://doi.org/10.1093/jac/dkg447

23. Diallo K, Thilly N, Luc A, et al. Management of bloodstream infections by infection specialists: an international ESCMID cross-sectional survey. Int J Antimicrob Agents. 2018;51(5):794-798. https://doi.org/10.1016/j. ijantimicag.2017.12.010

24. Eliakim-Raz N, Yahav D, Paul M, Leibovici L. Duration of antibiotic treatment for acute pyelonephritis and septic urinary tract infection -7 day or less versus longer treatment: systematic review and meta-analysis of randomized controlled trials. J Antimicrob Chemother. 2013;68(10):2183-2191. https://doi. org/10.1093/jac/dkt177

25. Havey TC, Fowler RA, Daneman N. Duration of antibiotic therapy for bacteremia: a systematic review and meta-analysis. Crit Care. 2011;15(6):R267. https:// doi.org/10.1186/cc10545

26. Daneman N, Rishu AH, Xiong W, et al. Duration of antimicrobial treatment for bacteremia in Canadian critically ill patients. Crit Care Med. 2016;44(2):256264. https://doi.org/10.1097/CCM.0000000000001393

27. Nelson AN, Justo JA, Bookstaver PB, Kohn J, Albrecht H, Al-Hasan MN. Optimal duration of antimicrobial therapy for uncomplicated gramnegative bloodstream infections. Infection. 2017;45(5):613-620. https://doi. org/10.1007/s15010-017-1020-5

28. Chotiprasitsakul D, Han JH, Cosgrove SE, et al. Comparing the outcomes of adults with Enterobacteriaceae bacteremia receiving short-course versus prolonged-course antibiotic therapy in a multicenter, propensity score-matched cohort. Clin Infect Dis. 2018;66:172-177. https://doi.org/10.1093/cid/cix767

29. Doi A, Morimoto T, Iwata K. Shorter duration of antibiotic treatment for acute bacteraemic cholangitis with successful biliary drainage: a retrospective cohort study. Clin Microbiol Infect. 2018;24(11):1184-1189. https://doi. org/10.1016/j.cmi.2018.01.021

30. Giannella M, Pascale R, Toschi A, et al. Treatment duration of Escherichia coli bloodstream infection and outcomes: retrospective single-center study. Clin Microbiol Infect. 2018;24(10):1077-1083. https://doi.org/10.1016/j. cmi.2018.01.013

31. Sousa A, Perez-Rodriguez MT, Suarez M, et al. Short- versus long-course therapy in gram-negative bacilli bloodstream infections. Eur J Clin Microbiol Infect Dis. 2019;38(5):851-857. https://doi.org/10.1007/s10096-019-03467-5.

32. Fabre V, Amoah J, Cosgrove SE, Tamma PD. Antibiotic therapy for Pseudomonas aeruginosa bloodstream infections: how long is long enough? Clin Infect Dis. 2019;69(11):2011-2014. https://doi.org/10.1093/cid/ciz223

33. Yahav D, Franceschini E, Koppel F, et al. Seven versus fourteen days of antibiotic therapy for uncomplicated gram-negative bacteremia: a noninferiority randomized controlled trial. Clin Infect Dis. 2019;69(7):1091-1098. https://doi. org/10.1093/cid/ciy1054

34. Hale AJ, Snyder GM, Ahern JW, Eliopoulos G, Ricotta D, Alston WK. When are oral antibiotics a safe and effective choice for bacterial bloodstream infections? an evidence-based narrative review. J Hosp Med. 2018;13(5):328-335. https://doi.org/10.12788/jhm.2949

35. Al-Hasan MN, Rac H. Transition from intravenous to oral antimicrobial ther- 
apy in patients with uncomplicated and complicated bloodstream infections. Clin Microbiol Infect. 2020;26(3):299-306. https://doi.org/10.1016/j. cmi.2019.05.012

36. Iversen K, Ihlemann N, Gill SU. Partial oral versus intravenous antibiotic treatment of endocarditis. N Engl J Med. 2019;380(5):415-424. https://doi. org/10.1056/NEJMoa1808312

37. Food and Drug Administration. FDA drug safety communication: FDA updates warnings for oral and injectable fluoroquinolone antibiotics due to disabling side effects. Accessed October 30, 2019. https://www.fda.gov/ drugs/drug-safety-and-availability/fda-drug-safety-communication-fda-updates-warnings-oral-and-injectable-fluoroquinolone-antibiotics

38. Mombelli G, Pezzoli R, Pinoja-Lutz G, Monotti R, Marone C, Franciolli M Oral vs intravenous ciprofloxacin in the initial empirical management of severe pyelonephritis or complicated urinary tract infections: a prospective randomized clinical trial. Arch Intern Med. 1999;159(1):53-58. https://doi. org/10.1001/archinte.159.1.53

39. Amodio-Groton M, Madu A, Madu CN, et al. Sequential parenteral and oral ciprofloxacin regimen versus parenteral therapy for bacteremia: a pharmacoeconomic analysis. Ann Pharmacother. 1996;30(6):596-602. http://doi. org/10.1177/106002809603000605

40. Park TY, Choi JS, Song TJ, Do JH, Choi SH, Oh HC. Early oral antibiotic switch compared with conventional intravenous antibiotic therapy for acute cholangitis with bacteremia. Dig Dis Sci. 2014;59(11):2790-2796. https://doi. org/10.1007/s10620-014-3233-0

41. Rieger KL, Bosso JA, MacVane SH, Temple Z, Wahlquist A, Bohm N Intravenous-only or intravenous transitioned to oral antimicrobials for Enterobacteriaceae-associated bacteremic urinary tract infection. Pharmacotherapy 2017;37(11):1479-1483. https://doi.org/10.1002/phar.2024

42. Thurber KM, Arnold JR, Narayanan PP, Dierkhising RA, Sampathkumar P. Comparison of intravenous and oral definitive antibiotic regimens in hospitalized patients with gram-negative bacteremia from a urinary tract infection. J Glob
Antimicrob Resist. 2019;18:243-248. https://doi.org/10.1016/j.jgar.2019.03.013

43. Tamma PD, Conley AT, Cosgrove SE, et al. Association of 30-day mortality with oral step-down vs continued intravenous therapy in patients hospitalized with Enterobacteriaceae bacteremia. JAMA Intern Med. 2019;179(3):316323. https://doi.org/10.1001/jamainternmed.2018.6226

44. Mercuro NJ, Stogsdill P, Wungwattana M. Retrospective analysis comparing oral stepdwon therapy for Enterobacteriaceae bloodstream infections: fluoroquinolones versus B-lactams. Int J Antimicrob Agents. 2018;51(5):687-692. https://doi.org/10.1016/j.ijantimicag.2017.12.007

45. Kutob LF, Justo JA, Bookstaver PB, et al. Effectiveness of oral antibiotics for definitive therapy of gram-negative bloodstream infections. Int J Antimicrob Agents. 2016;48(5):498-503. https//doi.org/10.1016/j.ijantimicag.2016.07.013

46. Punjabi $C$, Tien $V$, Meng $L$, et al. Oral fluoroquinolone or trimethoprimsulfamethoxazole vs ß-lactams as step-down therapy for Enterobacteriaceae bacteremia: systematic review and meta-analysis. Open Forum Infect Dis. 2019;6(10):ofz364. https://doi.org/10.1093/ofid/ofz364

47. Chen Al, Bilker WB, Hamilton KW. Blood culture utilization at an academic hospital: addressing a gap in benchmarking. Infect Control Hosp Epidemiol. 2018:39(11):1353-1359. http://doi.org/10.1017/ice.2018.231

48. Canzoneri CN, Akhavan BJ, Tosur Z, Andrade PEA, Aisenberg GM. Follow-up blood cultures in gram-negative bacteremia: are they needed? Clin Infect Dis. 2017;65(11):1776-1779. https://doi:10.1093/cid/cix648

49. Wiggers JB, Xiong W, Daneman N. Sending repeat cultures: is there a role in the management of bacteremic episodes? (SCRIBE study). BMC Infect Dis. 2016:16:286-295. https://doi.org/10.1186/s12879-016-1622-z

50. Kang CK, Kim ES, Song KH, et al. Can a routine follow-up blood culture be justified in Klebsiella pneumoniae bacteremia? a retrospective case-control study. BMC Infect Dis. 2013;13(1):365-372. https://doi.org/10.1186/1471-2334-13-365

51. Bates DW, Goldman L, Lee TH. Contaminant blood cultures and resource utilization: the true consequences of false-positive results. JAMA. 1991;265(3):365-369. https://doi:10.1001/jama.1991.03460030071031 